\title{
O DIREITO PODE OBRIGAR ALGUÉM A SER FRATERNO? A SANÇÃO COMO INSTRUMENTO DE EFETIVIDADE DO PRINCÍPIO DA FRATERNIDADE
}

\author{
Augusto César Leite de Resende ${ }^{1}$
}

DOI: https://doi.org/10.47306/978-65-88213-03-2.64-78

Sumário: 1 Introdução; 2 A fraternidade como categoria jurídica; 3 A força normativa do princípio da fraternidade: o papel da sanção na implementação dos deveres fraternos; 4 Considerações finais; Referências.

\section{Introdução}

A enfermidade COVID-19, causada pelo coronavírus SARS-COV-2, provocou uma crise sanitária mundial, tanto que em 11 de março de 2020, a Organização Mundial da Saúde declarou a COVID-19 uma pandemia. O novo vírus tem altíssima taxa de transmissibilidade, disseminando-se muito facilmente entre as pessoas, ou seja, é extremamente contagiosa. Além disso, a mencionada enfermidade tem taxa de letalidade de aproximadamente $4 \%$ e as autoridades sanitárias afirmam que não há medicamento nem vacina comprovadamente eficaz para combater a COVID-19, de modo que a única maneira de controlar a propagação da doença é o isolamento social, sob pena de colapso dos sistemas público e privado de saúde (BRANDÃO, 2020).

A superação da crise sanitária e o controle da COVID-19 perpassam necessariamente pela aplicação do princípio da fraternidade, na medida em que o comportamento das pessoas tem importante papel na propagação e na contenção do vírus, como a adoção da chamada etiqueta respiratória, o uso de máscara, higiene pessoal com álcool em gel, em especial das mãos, por exemplo.

A partir desse contexto, o objetivo principal do presente trabalho é propor, através de uma pesquisa dedutiva e bibliográfica, que a sanção é um instrumento jurídico que promove, em alguma medida, a exigibilidade, o cumprimento e a efetividade do princípio constitucional da fraternidade na ordem jurídica brasileira.

\footnotetext{
${ }^{1}$ Professor de Direitos Humanos e Fundamentais da Universidade Tiradentes - UNIT. Doutor em Direito pela Pontifícia Universidade Católica do Rio Grande do Sul. Mestre em Direito Econômico e Socioambiental pela Pontifícia Universidade Católica do Paraná. Promotor de Justiça em Sergipe. E-mail: aclresende@bol.com.br.
} 


\section{A fraternidade como categoria jurídica}

A fraternidade foi reconhecida, interpretada e praticada politicamente pela primeira vez na Idade Moderna com a Revolução Francesa de 1789, encravada na trilogia da "liberdade, igualdade e fraternidade", ou seja, com o movimento social-revolucionário francês do final do século XVIII a fraternidade passa a ter uma dimensão política, mas que, em seguida, desaparece da cena pública e cai no esquecimento (BAGGIO, 2008b, p. 7-8), fato esse que veio a influenciar a construção do pensamento político e jurídico da sociedade ocidental nos séculos XIX e XX, tanto que o texto formal da Constituição Federal de 1988 não se refere expressamente à fraternidade.

Por outro lado, percebe-se que o processo de reconstitucionalização da Europa após a Segunda Guerra Mundial, notadamente na Espanha, inspirado na Declaração Universal dos Direitos Humanos de 1948, incorporou nas Cartas Magnas valores jurídico-políticos superiores, ou seja, entidades axiológicas universais e supremas sob as quais deve basear-se a ordem jurídica num Estado Constitucional de Direito da contemporaneidade. (CUNHA, 2017, p. 39). A Constituição espanhola de 1978 é particularmente importante, nesse aspecto, porque consagrou expressa e formalmente em seu corpo os valores supremos da Liberdade, da Igualdade e da Justiça, que se encaminham para a Fraternidade. (CUNHA, 2017, p. 39).

No Brasil, a fraternidade não está prevista expressamente no texto formal da Constituição Federal de 1988. No entanto, "a constituição escrita não exclui a existência de normas, de nível constitucional, não escritas" (LISBOA, 2014, p. 67), razão pela qual a constituição formal pode ser complementada por normas constitucionais materiais. Tradicionalmente, a Constituição é classificada em formal e material. A consequência desta separação, imposta pela sacralização do poder constituinte efetivada pelo constitucionalismo liberal do século XIX, foi a negação da existência de outras fontes de direito constitucional, para além do poder constituinte, instituidor da constituição formal e das emendas constitucionais (EKMEKDJIAN, 1999, p. 22-23). Com o passar do tempo, as noções de constituição material e constituição formal foram retomadas pela teoria do direito, em especial por Hans Kelsen, com o objetivo de aclarar a sua ideia de hierarquia normativa. (CONTRERAS, 2013, p. 16).

Para o jurista austríaco, a "constituição no sentido formal é certo documento solene, um conjunto de normas jurídicas que pode ser modificado apenas com a observância de prescrições especiais cujo propósito é tornar mais difícil a modificação dessas normas" (KELSEN, 2005, p. 182), enquanto que a constituição em sentido material consiste na "norma 
positiva ou as normas positivas através das quais é regulada a produção das normas jurídicas gerais". (KELSEN, 2009, p. 247).

A constituição em sentido formal se revela como um conjunto de normas, que regulam a vida da sociedade e do Estado, instituídas pelo poder constituinte e plasmadas em um texto solene, com primazia em relação às demais leis estatais (VAZ, 2012, p. 55). Por sua vez, a constituição material deve ser entendida como um "conjunto de normas em que se percebe o caráter constitucional a partir de seu conteúdo, de sua matéria” (OMMATI, 2017, p. 9), independentemente de terem sido produzidas por um poder constituinte ou por um procedimento qualificado e distinto do processo legislativo das leis infraconstitucionais. É possível, portanto, identificar normas constitucionais, fora do texto formal da Constituição, quando elas disciplinarem matérias com dignidade constitucional intrínseca. (VAZ, 2012, p. 55).

A Constituição é um sistema aberto de regras e princípios (MIRANDA, 2011, p. 204), ou seja, uma obra incompleta, que vai além da Constituição formal, fruto do poder constituinte, de modo a partir o reconhecimento e a identificação de normas constitucionais fora do texto formal da Carta Magna, na medida em que para além de um conceito formal de Constituição, há um conceito material (SARLET, 2015, p. 80). A constitucionalização contemporânea do direito, fortemente influenciada pelo pós-positivismo, não se limita ao texto formal e expresso da Constituição, abarcando princípios implícitos e os tratados internacionais de direitos humanos (SCHIER, 2015), que passam a ser elementos integrantes da Constituição material, conceituada por José Joaquim Gomes Canotilho (2011, p. 1.139) como:

[...] o conjunto de fins e valores constitutivos do princípio efectivo da unidade e
permanência de um ordenamento jurídico (dimensão objectiva), e o conjunto de
forças políticas e sociais (dimensão subjectiva) que exprimem esses fins ou valores,
assegurando a estes a respectiva prossecução e concretização, algumas vezes para
além da própria constituição escrita. Ao contrário do que muitas vezes se pensa e vê
escrito, a constituição material não se reconduz a um simples "poder de facto"
("relações de poder e influência", "facto político puro"), pois a constituição material
tem também uma função ordenadora. A chamada força normativa de constituição (K.
Hesse) pressupõe, a maior parte das vezes, a vontade de constituição, ou seja, a
explicitação na constituição escrita ou formal do complexo de fins e valores agitados
pelas constelações políticas e sociais a nível da constituição material.

Essa perspectiva permite identificar novas normas constitucionais independentemente de alteração formal da Constituição por meio de emendas, fruto do poder constituinte derivado reformador, "originadas de fatos e não da atuação legislativa dirigida a este fim" (LISBOA, 2014, p. 67). O costume, as convenções, as práticas políticas e interpretação judicial são exemplos de fontes que dão origem a normas constitucionais não escritas. (LISBOA, 2014, p. 67-68). 
O preâmbulo da Constituição Federal, a despeito da controvérsia existente acerca da normatividade de seu conteúdo, tema que aqui não se desenvolverá, indica quais os fins a serem alcançados pelo ordenamento jurídico constitucional e, por essa razão, é capaz de influenciar a interpretação de seus preceitos (PEREIRA JÚNIOR, 2015, p. 60) e, nessa linha de raciocínio, o texto preambular se revela verdadeira fonte de direito constitucional, dela podendo se extrair normas constitucionais não escritas. A esse respeito,

[...] vários são os enunciados de forte carga axiológica aduzidos no preâmbulo, todos eles partes constitutivas das formulações proposicionais disciplinadoras de condutas intersubjetivas, bastando lembrar que alguns desses magnos princípios, manipulados pelos juristas, pertencem à subclasse dos implícitos, como os primados da justiça, da segurança jurídica e da certeza do direito, que não são retomados expressamente no texto da Constituição, mas que, é certo, hão de repercutir com intensidade controlada em todas as normas do ordenamento. (CARVALHO, 2010, p. 302).

O preâmbulo da Constituição da República é claro ao se referir a uma sociedade brasileira fraterna, servindo-se, nesse aspecto, como fonte do princípio constitucional implícito da fraternidade. Segundo as pioneiras lições de Carlos Augusto Alcântara Machado e Clara Machado, a fraternidade é uma categoria jurídica positivada no ordenamento jurídico nacional e extraída do Preâmbulo da Constituição e da própria carta constitucional, que enunciam os valores estruturantes do Estado brasileiro e os objetivos fundamentais da República Federativa do Brasil, dentre os quais, destaca-se, a construção de uma sociedade fraterna, pluralista, sem preconceitos, livre, justa e solidária. Enfim, a fraternidade está positivada implicitamente no ordenamento jurídico brasileiro, apresentando-se como categoria jurídico-constitucional indispensável para o advento do constitucionalismo fraternal. (MACHADO, 2017, p. 219).

Sobre esse ponto, assim leciona Reynaldo Soares da Fonseca (2019, p. 169-170):

No caso brasileiro, a Constituição vigente absorveu os três valores da Revolução de
1789 ao registrar como primeiro objetivo da República Federativa do Brasil a
construção de uma sociedade livre (liberdade), justa (igualdade) e solidária
(fraternidade) - art. $3^{\circ}$. [...] Assim, o constitucionalismo moderno pátrio ultrapassa o
liberalismo (constitucionalismo liberal - dimensão política) e a social democracia
(constitucionalismo social - dimensão social), enveredando pelo chamado
constitucionalismo fraternal (ou altruístico).

A constitucionalização da fraternidade permite a construção daquilo de Michele Carducci (2003, p. 50) chamou de um "direito constitucional como responsabilidade para com os outros" ou um "direito constitucional altruísta". O ser humano não vive isolado, mas, ao contrário, o homem vive consigo mesmo, numa comunidade e num Estado e, por essa razão, “não existe ação humana que não seja contemporaneamente um 'responder' a si mesmos, aos outros e à lei" (CARDUCCI, 2003, p. 51). Filippo Pizzolato (2008, p. 114) aduz que a fraternidade é uma espécie de solidariedade horizontal, distinta da solidariedade vertical, caracterizada, esta, por ser uma forma de intervenção do Estado com o intuito de reduzir as 
desigualdades sociais e permitir o livre desenvolvimento da pessoa humana, ao passo que a fraternidade se refere a uma espécie de socorro mútuo entre os próprios indivíduos, sendo o Estado um mero fiador externo.

A fraternidade permite "dar fundamento à ideia de uma comunidade universal, de uma unidade de diferentes, na qual os povos vivam em paz entre si, sem o jugo de um tirano, mas no respeito das próprias identidades" (BAGGIO, 2008a, p. 53). Mais do que isso, a fraternidade tem a aptidão para promover a paz social, o equilíbrio entre liberdade e igualdade, entre responsabilidade individual e solidariedade e entre bens particulares e bem comum. (MACHADO, 2017, p. 215).

O jurista Luis Fernando Barzotto (2018) ensina que a fraternidade se apresenta como um dever de reconhecer como irmão aquele que não é, por consanguinidade, irmão, ou seja, reconhecer o próximo como igual em dignidade e, deste modo, merecedor de igual consideração e respeito profundo. E reconhecer a pessoa humana como irmão e, destarte, como membro de uma mesma comunidade, significa assumir a responsabilidade por ele (BARZOTTO, 2018, p. 82).

Contudo, postas, alhures, as premissas básicas, ainda que em linhas gerais e superficiais, acerca da consagração constitucional e da delimitação do conteúdo da fraternidade, é mister levar a sério o princípio constitucional da fraternidade, vale dizer, é necessário avançar e refletir sobre a força normativa e coativa da fraternidade à luz do sistema jurídico brasileiro e, para tanto, indagamos: é juridicamente possível obrigar alguém a ser fraterno?

\section{A força normativa do princípio da fraternidade: o papel da sanção na implementação dos deveres fraternos}

O princípio da fraternidade é, enquanto elemento inserido no mundo jurídico, prescritivo, donde se extrai deveres jurídicos de socorro impostos pela legislação ao particular, não se confundindo, portanto, com as formas voluntárias de ajuda ao próximo, como a filantropia (PIZZOLATO, 2008, p. 114). Assim, a prática da fraternidade pode ser incentivada ou imposta pela lei.

Segundo Clara Machado (2017, p. 62), o reconhecimento da força normativa da fraternidade a partir de sua consagração no sistema jurídico nacional como regra ou princípio lança novos olhares sobre os direitos e, especialmente dos deveres fundamentais. Por isso, a fraternidade enquanto norma jurídica produz efeitos jurídicos no plano do mundo fático.

A esse respeito, Clara Machado (2017, p. 65) diz: 
[...] fraternidade possui natureza normativa principiológica, na medida em que está no nível reflexivo da ordem jurídica, servindo tanto para a construção hermenêutica de outras regras, bem como para ordenar, em razão de seu caráter deôntico, que algo seja concretizado, de acordo com as circunstâncias fáticas e jurídicas existentes. Defendese, portanto, que fraternidade é princípio fundamental introduzido de maneira expressa ou implícita no texto constitucional que atua como vetor interpretativo na construção do significado de outros enunciados, além de fomentar no indivíduo o reconhecimento da dignidade humana e realizar o princípio da responsabilidade no âmbito estatal, individual e coletivo.

O princípio (ou regra) da fraternidade obriga os homens a desenvolver uma atividade que promova o progresso material e espiritual da sociedade, de modo que todos deverão contribuir, de alguma forma, para o bem-estar do outro e da sociedade, na medida em que a fraternidade não significa apenas não prejudicar o próximo, mas, sobretudo, fazer o bem ao outro (PIZZOLATO, 2008, p. 119-120). Compreende, portanto, o dever de concorrer positivamente para bem-estar socioambiental, econômico e espiritual das pessoas. (PIZZOLATO, 2008, p. 120-121).

Hodiernamente, não mais se discute a força normativa da Carta Magna (HESSE, 1991, p. 19) e, como dito alhures, a fraternidade é um princípio constitucional implícito. Logo, ela é norma jurídica, dotada de imperatividade e, por isso mesmo, obrigatória e vinculativa. Em suma, conclui-se, com Carlos Augusto Alcântara Machado (2017, p. 208), que a responsabilidade social entre cidadãos é uma decorrência normativo-constitucional da fraternidade e, de acordo com a lição de Clara Machado (2017, p. 66), viabiliza a conscientização e a realização dos direitos e deveres fundamentais dos indivíduos.

A fraternidade impõe, nesse contexto, obrigações negativas e positivas às pessoas, no sentido de que não basta não ser fraterno, não é suficiente abster-se da prática de condutas não fraternas, como, por exemplo, o consumo inconsciente (RESENDE; MOLINARO, 2019), eis que há também o dever de, a partir da lição de Luis Fernando Barzotto (2018), adotar ações concretas de solidariedade, de respeito e de reciprocidade para com o outro. E "quando um indivíduo recusa-se a ver o outro como um igual, o Direito deve obrigá-lo ao reconhecimento". (GABARDO, 2017, p. 83).

A fraternidade se apresenta como princípio ativo, motor do comportamento, da ação dos homens, que impõe, como diz Marco Aquini (2008, p. 133), deveres para com a comunidade e para com o outro. O princípio jurídico da fraternidade "responsabiliza cada indivíduo pelo outro e, consequentemente, pelo bem da comunidade, e promove a busca de soluções para a aplicação dos direitos humanos que não passam necessariamente, todas, pela autoridade pública" (AQUINI , 2008, p. 138-139), valorizando-se, com isso, o papel das entidades privadas e do próprio cidadão no respeito e da responsabilidade pelo outro. 
Enfim, na qualidade de categoria jurídico-constitucional, a fraternidade tem força prescritiva (AQUINI , 2008, p. 140), dela podendo se extrair, pela via legislativa ordinária ou jurisdicional, obrigações, proibições e permissões. Evidentemente que o simples reconhecimento do dever jurídico de ser fraterno ou de abster-se de não ser fraterno é, por si só, incapaz de provocar uma mudança de comportamento. É preciso, desse modo, pensar e compreender as funções do Direito na contemporaneidade e, especialmente, refletir sobre quais instrumentos jurídicos existentes no sistema jurídico nacional poderão ser utilizados para garantir a plena eficácia do princípio da fraternidade e, consequentemente, para fomentar mudanças de comportamento que permitam criar uma sociedade fraterna, sustentável e mais justa para todos. E, nesse ponto, a sanção tem papel fundamental para a efetividade da fraternidade ${ }^{2}$.

A teoria jurídica desenvolvida a partir dos anos 1960 praticamente ignorou a dimensão coercitiva do direito e a importante função que a sanção exerce no sistema jurídico, particularmente influenciada pelo pensamento hartiano (CHRISMANN, 2013). O papel da coerção, entretanto, não pode ser simplesmente deixado de lado pela teoria do direito, uma vez que muitas pessoas obedecem a lei por causa das consequências negativas que possam sofrer em caso de desobediência.

Como bem colocado por Frederick Schauer (2015, p. 1), a característica mais visível do direito é que ele obriga as pessoas a adotarem condutas que elas não desejariam realizar. E o direito possui mecanismos para compelir as pessoas a moldarem suas condutas de acordo com as normas jurídicas vigentes, como, por exemplo, a sanção. É verdade que existem pessoas que cumprem espontaneamente o direito, ainda que seja contrário aos seus interesses privados, mas, no geral, as pessoas somente fazem aquilo que desejam ou que atenda aos seus interesses particulares, salvo se alguma força externa os obrigue a realizar o contrário. (SCHAUER, 2015, p. 05).

Para Mauricio García-Villegas (2009, p. 242), o fenômeno do desrespeito à legislação é resultado de incentivos para não a cumprir, que se originam, dentre outros fatores, da incapacidade institucional do Estado para punir os infratores, funcionando a ausência de sancionamento efetivo como um importante elemento catalisador para a violação das normas jurídicas. Não é por outro motivo, que a força coercitiva do direito é necessária para a própria efetividade das normas jurídicas, eis que, reforce-se, a regra é que “[...] em cenários em que não há punição, as pessoas tendem a agir de forma egoística e buscam sempre o melhor resultado

\footnotetext{
${ }^{2} \mathrm{O}$ presente trabalho de pesquisa não analisa o papel das designadamente sanções premiais, mas apenas as punitivas em sentido estrito.
} 
possível para si [...]" (CHRISMANN, 2013, p. 48), ainda que para tanto tenham que descumprir a legislação.

A inobservância das normas jurídicas decorre, dentre outros motivos, por fatores utilitaristas, no sentido de que o infrator calcula, racional e egoisticamente, os custos e os benefícios do inadimplemento, o que seria especialmente catalisado com a falta de sanções eficazes para os casos de violação das regras e dos princípios, o que inclui a fraternidade (OLIVEIRA; CUNHA, 2017, p. 282). Veja-se:

A constatação é a de que as pessoas tendem a agir de modo diferente, ou seja, em contrariedade ao Direito, se com ele não concordam e não há sanção que busque efetivá-lo. A coerção, ainda, é vital para definir padrões de conduta tanto do cidadão como autoridades estatais, ainda que seus atos fujam da legalidade com a melhor das intenções, pois isto significaria uma indesejada discricionariedade. (PUGLIESE, 2015, p. 250).

Além disso, o indivíduo pode obedecer à legislação movido por diversos fatores, distintos da ameaça de punição, como, por exemplo, questões de natureza moral (reprovação ética da conduta pelo próprio agente) ou questões pessoais (receio de má reputação) (TYLER, 2006, p. 3-4). Os norte-americanos cumprem, por exemplo, as leis não porque temem punições, mas porque acreditam na legitimidade das leis e das ordens emanadas das autoridades e das instituições legais do país (OLIVEIRA; CUNHA, 2017, p. 280). Por isso, o temor à sanção não é, evidentemente, o único fator motivacional de obediência às normas jurídicas pelos sujeitos de direito (ZANITELLE, 2015, p. 94), mas, sem dúvidas, "la ameaza de la sanción cumple un papel fundamental en el Estado: no sólo disuade a los vivos de que incumplan, sino que los domestica, los acostumbra a respetar las normas sin que ello obedezca a un cálculo estratégico”. (GARCÍA-VILLEGAS, 2009, p. 271) ${ }^{3}$.

Nesse cenário, a aplicação da pena não deve ser encarada unicamente como uma medida retributiva ou de vingança ao agente público ímprobo, pois possui um caráter predominantemente preventivo. (BLANCHET; GABARDO, 2012). A esse propósito,

\begin{abstract}
A razão de ser da sanção não reside no prejuízo a ser causado o infrator, e sim na necessidade de dissipação da intranquilidade gerada, com a consequente restauração da soberania do direito, principal alicerce da segurança que deve reinar nas relações sociais. A proporção que deve existir entre o ilícito e a sanção deve ser correlata à existente entre as forças morais presentes no temor causado aos cidadãos e no lenitivo que será utilizado para tranquiliza-los (GARCIA; ALVES, 2014, p. 579).
\end{abstract}

O jurista italiano Norberto Bobbio (1968, p. 4) sustenta que o termo "sanção" possui na linguagem jurídica dois significados: a) um técnico, próprio do direito constitucional,

\footnotetext{
3 “A ameaça da sanção cumpre um papel fundamental no Estado: não só dissuade os vivos de violar as normas, mas os domestica, os acostuma a respeitar as regras sem que isso se deva a um cálculo estratégico" (tradução livre do autor).
} 
correspondendo ao ato de concordância do Chefe do Poder Executivo com a lei aprovada pelo Parlamento; e b) um geral, comum à linguagem moral e às ciências sociais, que no Direito significa uma medida prevista pelo próprio ordenamento jurídico para reforçar a observância das normas jurídicas e, eventualmente, corrigir os efeitos decorrentes da sua desobediência. Assim, a punição é um expediente utilizado pelos sistemas normativos para obter a máxima observância de suas normas ou, dito de outra forma, para impedir ao máximo o seu incumprimento, servindo, assim, como uma medida preventiva ou sucessiva à violação do direito (BOBBIO, 1968, p. 6).

Os ordenamentos jurídicos preveem medidas de encorajamento e desencorajamento com o escopo de reforçar o cumprimento das normas jurídicas e são exclusivamente psicológicas porque são formas de pressão exercidas sobre a consciência mental da pessoa (BOBBIO, 1968, p. 11). Segundo Norberto Bobbio (1968, p. 11),

[...] la tipica tecnica dello scoraggiamento consiste nella rappresentazione delle conseguenze spiacevole di un'infrazione, così come la tipica tecnica dell'incoraggiamento consiste nella rappresentazione delle conseguenze gradevoli dell'osservanza ${ }^{4}$.

Note-se que a sanção não é propriamente a medida de desencorajamento, mas sim a perspectiva da aplicação da pena (MAGALHÃES E GERRA, 2008, p. 5.031). As sanções são importantes mecanismos de incentivo para a ação ou inação desejada pelo direito ou, mais especificamente, pelo princípio da fraternidade. Inclusive, Scott Shapiro (2011, pos. 995-1001) reconhece a importante função da punição para o ordenamento jurídico, ao afirmar que:

Sanctions, in other words, are only one kind of tool that the law may use to motivate behavior. Duties are another; rewards yet a third type. A general theory about the nature of law must adequately represent all of the techniques that the law has at its disposal and not myopically privilege one to the exclusion of all others ${ }^{5}$.

A coerção é uma fonte importante de eficácia do direito e, por consequência, de realização dos seus fins (SCHAUER, 2015, p. 52), na medida em que a tomada de decisão das pessoas pode ser influenciada pelas normas jurídicas punitivas, embora se reconheça que as decisões possam ser tomadas por outros motivos. Por isso, defende-se que a sanção é uma ferramenta que tem o potencial de induzir ações ou omissões das pessoas com o objetivo de se

\footnotetext{
4 “A típica técnica de desencorajamento consiste na representação de consequências negativas de uma infração, assim como a típica técnica de encorajamento consiste na representação de consequências positivas da observância" (tradução livre do autor).

5 "Sanções, em outras palavras, são apenas um tipo de ferramenta que o direito pode usar para motivar comportamentos. Deveres são outros; recompensas ainda um terceiro tipo. Uma teoria geral sobre a natureza do direito deve representar adequadamente todas as técnicas que o direito tem à sua disposição e não privilegiar de forma míope uma, excluindo todas as outras" (tradução livre do autor).
} 
cumprir as finalidades desejadas pela norma jurídica, inclusive pelo princípio da fraternidade. (DELGADO, 2016, p. 197).

As pessoas podem obedecer à legislação por diversos motivos, sacrificando, inclusive, seus próprios desejos e interesses pessoais. Porém, não existem pesquisas empíricas que demonstram seguramente que a maioria dos indivíduos cumpre voluntariamente as normas jurídicas, ainda que estas afetem negativamente seus interesses particulares ou que sejam contrárias ao julgamento pessoal acerca da correção moral ou política da decisão jurídica. (SCHAUER, 2015, p. 98).

O direito sem coerção é praticamente ineficaz, eis que as taxas de descumprimento da legislação são muito maiores naqueles casos de proibições ou obrigações jurídicas desprovidas de sanção (SCHAUER, 2015, p. 65-66), ou seja, a obediência à lei, independentemente da perspectiva da punição, é mais incomum do que se imagina (SCHAUER, 2015, p. 75). Aliás, segundo pesquisa realizada por Fabiana Luci de Oliveira e Luciana Gross Cunha (2017, p. 288289), as infrações pelas quais os brasileiros acham mais provável serem punidos, são as que foram menos realizadas pelos entrevistados, demonstrando-se, assim, uma correspondência inversa entre o comportamento de desobediência e a percepção do risco de sanção.

Por essas razões, Federick Schauer (2015, p. 75) sustenta que as sanções são extremamente importantes para garantir o cumprimento do direito e, desse modo, coibir, na medida do possível, comportamentos ilícitos fundados, por exemplo, em motivações egoístas ou em erros de percepção ou de interpretação da própria norma. A propósito:

And thus in a environment in which genuine and sanction-independent obedience is
rare, coercion through the threat of sanctions emerges as the principal mechanism for
securing the obedience that turns out to be so often necessary. Even if, contra Austin,
sanctions are not an essential component of the very idea of legal obligation, they
seems nonetheless crucial in promoting a motivation to obey and thus in promoting
compliance with law.

A sanção funciona como um instrumento que tem por finalidade fazer com que o direito se cumpra, evitando-se, por consequência, a violação das normas jurídicas (YEUNG, 1999). Alice Voronoff (2018, p. 104-106) leciona que a sanção não é simplesmente uma consequência do ilícito, mas também instrumento a serviço de valores e objetivos previstos na legislação e almejados pela sociedade, produzindo efeitos prospectivos, com o escopo de assegurar e

\footnotetext{
6 "Assim, em um ambiente em que a obediência genuína e independente da sanção é rara, a coerção através da ameaça de sanções surge como o principal mecanismo para assegurar a obediência que acaba por ser tão necessária. Mesmo que, contra Austin, as sanções não sejam um componente essencial da própria idéia de obrigação jurídica, elas parecem, não obstante, cruciais para promover uma motivação para obedecer e, assim, promover o cumprimento da lei" (tradução livre do autor).
} 
promover a conformação de condutas, conduzindo o comportamento das pessoas em direção aos objetivos perseguidos pelo Direito.

O princípio da fraternidade absolutamente dissociado da coerção não é plenamente eficaz, de modo que a sanção poderá ser utilizada a induzir comportamentos fraternos ou impedir a prática de atos não fraternos. No caso específico do combate à pandemia de COVID19, tem-se a implementação, por parte das autoridades governamentais, de medidas sanitárias com vistas a impedir ou minimizar a propagação do vírus e, por consequência, diminuir o número de infectados e de mortes. Dentre as medidas adotadas, destacam-se o uso obrigatório da máscara, proibição de aglomeração de pessoas e o fechamento de empreendimentos comerciais.

O descumprimento das chamadas medidas de isolamento social pode ensejar a responsabilização penal, civil e administrativa dos infratores. Por exemplo, o art. 288 do Código Penal tipifica a conduta de "infringir determinação do poder público, destinada a impedir introdução ou propagação de doença contagiosa: pena - detenção, de um mês a um ano, e multa". Do mesmo modo, o desrespeito às determinações estatais pode ensejar a responsabilidade administrativa da pessoa, com a aplicação de multa. Aqui, a perspectiva da punição poderá ser um bom mecanismo catalisador do cumprimento das medidas de isolamento social e de prevenção ao contágio, que têm fulcro na fraternidade, na medida em que diminuem a circulação do vírus e do risco de contaminação, contribuindo para a efetividade dos direitos à vida, integridade física e à saúde das pessoas, notadamente daquelas mais expostas ao SARSCOV-2, que são os pobres.

Não se trata de se fazer uma ode ao punitivismo em nome da fraternidade, mas apenas reconhecer que a coerção tem um importante papel para a implementação do princípio da fraternidade, eis que as pessoas podem cumpri-lo com o intuito único de apenas obedecer a Constituição, auferir prestígio ou promoção profissional, mas, outros somente observarão o princípio da fraternidade pelo simples receio da punição. (SCHAUER, 2015, p. 41).

Por derradeiro, ressalte-se que o uso da sanção deve se dar na forma e no modo prescritos pela legislação, respeitados os direitos humanos e fundamentais dos indivíduos, dentre os quais os princípios da legalidade, da irretroatividade e do devido processo legal, tema que aqui não se desenvolverá. 


\section{Considerações finais}

O objetivo principal do presente trabalho foi propor, através de uma pesquisa dedutiva e bibliográfica, que a sanção é um instrumento jurídico que promove, em alguma medida, a exigibilidade, o cumprimento e a efetividade do princípio constitucional da fraternidade na ordem jurídica brasileira.

Para tanto, partiu-se da premissa que a fraternidade é um princípio constitucional implícito no sistema jurídico brasileiro, extraído do Preâmbulo da Constituição da República, e que, por isso, tem caráter deontológico. Nesse diapasão, o princípio da fraternidade é prescritivo, no sentido de que impõe às pessoas deveres negativos e positivos, vale dizer, de adotarem condutas fraternas e de se absterem de praticar comportamentos não fraternos, a exemplo da intolerância ou indiferença, podendo-se extrair dele, portanto, obrigações, proibições e permissões.

Postas tais premissas, verificou-se que para a efetividade do princípio da fraternidade não é suficiente o seu mero reconhecimento como norma jurídica de natureza constitucional nem a sua delimitação conceitual, fazendo-se mister o uso dos instrumentos existentes no ordenamento jurídico vocacionados a garantir o cumprimento do Direito, a exemplo da punição.

Assim, concluiu-se que a sanção é um mecanismo presente do sistema jurídico brasileiro que, se bem utilizada, tem potencial para fomentar o respeito, a proteção e a promoção da fraternidade no Brasil.

\section{REFERÊNCIAS}

AQUINI, Marco. Fraternidade e direitos humanos. In: BAGGIO, Antonio Maria (org.). O princípio esquecido: a fraternidade na reflexão atual das ciências políticas. Vargem Grande Paulista: Editora Cidade Nova, p. 127-151, 2008.

BAGGIO, Antonio Maria. A ideia de fraternidade em duas: revoluções: Paris 1789 e Haiti 1791. In: BAGGIO, Antonio Maria (org.). O princípio esquecido: a fraternidade na reflexão atual das ciências políticas. Vargem Grande Paulista: Editora Cidade Nova, p. 25-55, 2008a.

BAGGIO, Antonio Maria A redescoberta da fraternidade na época do "terceiro 1789". In: BAGGIO, Antonio Maria (org.). O princípio esquecido: a fraternidade na reflexão atual das ciências políticas. Vargem Grande Paulista: Editora Cidade Nova, p. 7-24, 2008 b.

BARZOTTO, Luis Fernando. Fraternidade: uma aproximação conceitual. In: MACHADO, Carlos Augusto Alcântara; JABORANDY, Clara Cardoso Machado; BARZOTTO, Luciane Cardoso (orgs.). Direito e fraternidade: em busca de concretização. Aracaju: EDUNIT, p. 79-89, 2018. 
BLANCHET, Luiz Alberto; GABARDO, Emerson. A aplicação dos princípios de Direito Penal no Direito Administrativo: uma análise do princípio da insignificância econômica. A\&C - Revista de Direito Administrativo \& Constitucional, Belo Horizonte, ano 12, n. 47, jan./mar. 2012. Disponível em:

http://www.bidforum.com.br/PDI0006.aspx?pdiCntd=78333. Acesso em: 03 de jun. 2020.

BOBBIO, Norberto. Sanzione. Novissimo Digesto Italiano. Turim: Unione TipográficoEditrice Torinese, 1968.

BRANDÃO, Rodrigo. Coronavírus, estado de exceção sanitária e restrição a direitos fundamentais. Disponível em: https://www.jota.info/opiniao-e-analise/artigos/coronavirusestado-excecao-sanitaria-direitos-fundamentais-04042020. Acesso em: 03 jun. 2020.

CANOTILHO, José Joaquim Gomes. Direito constitucional e teoria da Constituição. 7. ed. Coimbra: Almedina, 2011.

CARDUCCI, Michele. Por um direito constitucional altruísta. Porto Alegre: Livraria do Advogado, 2003.

CARVALHO, Paulo de Barros. O preâmbulo e a prescritividade constitutivas dos textos jurídicos. Revista Direito GV, São Paulo, v. 6, n. 1, p. 295-312, jan. 2010.

CONTRERAS, Juan Manuel Terán y. El concepto de constitución material y la jerarquización normativa. Alegatos, Cidade do México, n. 83, p. 15-30, jan./abr. 2013.

CHRISMANN, Pedro Henrique Veiga. Repensando as sanções: uma análise interdisciplinar do fenômeno punitivo. Rio de Janeiro, 2013. 95p. Dissertação (Mestrado em Direito) Departamento de Direito, Pontifícia Universidade Católica do Rio de Janeiro, 2013.

CUNHA, Paulo Ferreira da. Direito fraterno humanista: novo paradigma jurídico. Rio de Janeiro: GZ Editora, 2017.

DELGADO, Pablo Soto. Sanciones administrativas como medidas de cumplimiento del Derecho: un enfoque funcional y responsivo aplicado al régimen sancionatorio ambiental. Revista Ius et Praxis, Talca, ano 22, n. 2, p. 189-226, 2016.

EKMEKDJIAN, Miguel Ángel. Manual de la constitución argentina. 4. ed. Buenos Aires: Depalma, 1999.

FONSECA, Reynaldo Soares da. O princípio constitucional da fraternidade: seu resgate no sistema de justiça. Belo Horizonte: Editora D’Plácido, 2019.

GABARDO, Emerson. Os perigos do moralismo político e a necessidade de defesa do direito posto na Constituição da República de 1988. A\&C - Revista de Direito Administrativo \& Constitucional, Belo Horizonte, ano 17, n. 70, p. 65-91, out./dez. 2017.

GARCIA, Emerson; ALVES, Rogério Pacheco. Improbidade administrativa. 7. ed. São Paulo: Saraiva, 2014. 
GARCÍA-VILLEGAS, Mauricio. Los incumplidores de reglas. In: GARCÍA-VILLEGAS, Mauricio (dir.). Normas de papel: la cultura del incumplimiento de reglas. Bogotá: Siglo del Hombre Editores y Dejusticia, 2009, p. 237-282.

HESSE, Konrad. A força normativa da Constituição, Tradução: Gilmar Ferreira Mendes, Sérgio Antônio Frabris Editor, Porto Alegre, 1991.

KELSEN, Hans. Teoria geral do direito e do Estado. 5. ed. São Paulo: Martins Fontes, 2005.

KELSEN, Hans. Teoria pura do direito. 8. ed. São Paulo: WMF Martins Fontes, 2009.

LISBOA, Carolina Cardoso Guimarães. Normas constitucionais não escritas. Lisboa: Almedina, 2014.

MACHADO, Carlos Augusto Alcântara. A fraternidade como categoria jurídica: fundamentos e alcance (expressão do constitucionalismo fraternal). Curitiba: Appris, 2017.

MACHADO, Clara. O princípio jurídico da fraternidade: um instrumento para proteção de direitos fundamentais transindividuais. Rio de Janeiro: Lumen Juris, 2017.

MAGALHÃES E GERRA, Marcel Vitor de. Sanção na Teoria do Direito de Bobbio: pesquisa enriquecida por apontamentos extraídos de ensaio inédito no Brasil, Sanzione, cedido pela família do autor ao Centro de Estudos Norberto Bobbio, em São Paulo. Anais do XVII Congresso Nacional do CONPEDI, Florianópolis: Fundação Boiteux, p. 5.025-5.047, 2008.

MIRANDA, Jorge. Teoria do Estado e da Constituição. Rio de Janeiro: Forense, 2011.

OLIVEIRA, Fabiana Luci de; CUNHA, Luciana Gross. A legitimidade das leis e das instituições de justiça na visão dos brasileiros. Contemporânea - Revista de Sociologia da UFSCar, São Carlos, v. 7, n. 2, jul./dez. 2017, p. 275-296.

OMMATI, José Emílio Medauar. Teoria da constituição. 6. ed. Rio de Janeiro: Lumen Juris, 2017.

PEREIRA JÚNIOR, Edilson Nobre. O preâmbulo e seu componente normativo. A\&C Revista de Direito Administrativo \& Constitucional, Belo Horizonte, ano 15, n. 59, p. 4761, jan./mar. 2015.

PIZZOLATO, Filippo. A fraternidade no ordenamento jurídico italiano. In: BAGGIO, Antonio Maria (org.). O princípio esquecido: a fraternidade na reflexão atual das ciências políticas. Vargem Grande Paulista: Editora Cidade Nova, p. 111-126, 2008.

PUGLIESE, William Soares; FORTES, Luiz Henrique Krassuski. The force the law, de Frederick Schauer. Revista da Faculdade de Direito - UFPR, Curitiba, vol. 60, n. 2, p. 249253, maio/ago. 2015.

RESENDE, Augusto César Leite de; MOLINARO, Carlos Alberto. O dever constitucional do consumo consciente: reflexões a partir do princípio da fraternidade. In: MACHADO, Carlos 
Augusto Alcântara; JABORANDY, Clara Cardoso Machado; POZZOLI, Lafayette (org.). Direitos humanos, agenda 2030 e desenvolvimento sustentável. Rio de Janeiro: Bonecker, p. 33-54, 2019.

SARLET, Ingo Wolfgang. A eficácia dos direitos fundamentais: uma teoria geral dos direitos fundamentais na perspectiva constitucional. 12. ed.. Porto Alegre: Livraria do Advogado, 2015.

SCHAUER, Frederick. The force of law. Cambridge: Harvard University Press, 2015.

SCHIER, Paulo Ricardo. Filtragem constitucional e ADPF 138. Gazeta do Povo. Curitiba, 21 de dezembro de 2015. Disponível em: http://www.gazetadopovo.com.br/vida-publica/justicae-direito/artigos/filtragem-constitucional-e-adpf-378-1841 mh3iwmui5eu9c76tn7ib9. Acesso em: 21 de maio de 2020.

SHAPIRO, Scott J. Legality. Cambridge: Harvard University Press, 2011, pos. 995-1001. Kindle.

TYLER, Tom R. Why people obey the law. New Jersey: Princeton University Press, 2006.

VAZ, Manuel Afonso. Teoria da constituição: o que é uma constituição, hoje? Coimbra: Coimbra Editora, 2012.

VORONOFF, Alice. Direito administrativo sancionador no Brasil: justificação, interpretação e aplicação. Belo Horizonte: Fórum, 2018.

YEUNG, Karen. Quantifying regulatory penalties: australian competition law penalties in perspective. Melbourne University Law Review, Melbourne, vol. 23, n. 2, p. 440-475, 1999. Disponível em: http://www.austlii.edu.au/au/journals/MULR/1999/18.html. Acesso em 02 jun. 2020.

ZANITELLE, Leandro Martins. Motivação para obediência e o debate regras versus princípios. Prisma Jurídico, São Paulo, v. 14, n. 1, p. 93-114, jan./jun. 2015. 